OPEN ACCESS

Edited by:

Jolanta Górska-Andrzejak,

Jagiellonian University, Poland

Reviewed by:

Maurizio De Pittà,

University of Chicago, United States

Eddy A. Van Der Zee

University of Groningen, Netherlands

${ }^{*}$ Correspondence:

Arturo Ortega

arortega@cinvestav.mx

Specialty section: This article was submitted to Integrative Physiology, a section of the journal

Frontiers in Physiology

Received: 29 September 2017

Accepted: 26 January 2018

Published: 12 February 2018

Citation:

Chi-Castañeda D and Ortega A (2018)

Glial Cells in the Genesis and

Regulation of Circadian Rhythms.

Front. Physiol. 9:88.

doi: 10.3389/fphys.2018.00088

\section{Glial Cells in the Genesis and Regulation of Circadian Rhythms}

\author{
Donaji Chi-Castañeda ${ }^{1,2}$ and Arturo Ortega ${ }^{1 *}$ \\ ${ }^{1}$ Laboratorio de Neurotoxicología, Departamento de Toxicología, Centro de Investigación y de Estudios Avanzados del \\ Instituto Politécnico Nacional, Ciudad de Mexico, Mexico, ${ }^{2}$ Soluciones para un México Verde S.A. de C.V., Ciudad de \\ Mexico, Mexico
}

Circadian rhythms are biological oscillations with a period of $\sim 24 \mathrm{~h}$. These rhythms are orchestrated by a circadian timekeeper in the suprachiasmatic nucleus of the hypothalamus, the circadian "master clock," which exactly adjusts clock outputs to solar time via photic synchronization. At the molecular level, circadian rhythms are generated by the interaction of positive and negative feedback loops of transcriptional and translational processes of the so-called "clock genes." A large number of clock genes encode numerous proteins that regulate their own transcription and that of other genes, collectively known as "clock-controlled genes." In addition to the sleep/wake cycle, many cellular processes are regulated by circadian rhythms, including synaptic plasticity in which an exquisite interplay between neurons and glial cells takes place. In particular, there is compelling evidence suggesting that glial cells participate in and regulate synaptic plasticity in a circadian fashion, possibly representing the missing cellular and physiological link between circadian rhythms with learning and cognition processes. Here we review recent studies in support of this hypothesis, focusing on the interplay between glial cells, synaptic plasticity, and circadian rhythmogenesis.

\section{Keywords: circadian rhythms, clock genes, glial oscillators, learning, memory, plasticity}

\section{INTRODUCTION}

Most light-sensitive organisms have an internal timekeeping mechanism to anticipate daily changes associated with the transition of day to night that is commonly known as "circadian clock". In 1959 , Halberg denominated "circadian rhythms" the biological rhythms that have a period of $\sim 24 \mathrm{~h}$ (Halberg, 1959). These rhythms regulate a large number of physiological and behavioral functions in vertebrates, such as hormone secretion, body temperature, metabolism, and even memory processes. The sleep-wake cycle is one the most studied rhythms (Schibler and Sassone-Corsi, 2002; Stratmann and Schibler, 2006; Walker and Stickgold, 2006).

Sleep is a highly conserved process (Hartse, 2011), and several hypotheses support the notion that sleep supersedes learning and memory, possibly through the control of synaptic plasticity (Benington and Frank, 2003; Frank and Benington, 2006; Frank, 2011; Fellin et al., 2012; Frank and Cantera, 2014; De Pittà et al., 2016). Synaptic plasticity refers to the biochemical processes by which synaptic strength changes in an activity-dependent fashion. These cellular cascades are a combination of post-translational modifications that change neural activity, and also result in the reshaping of synaptic terminals (Lohmann and Kessels, 2014). Depending on its temporal course, synaptic plasticity is distinguished into three classes: (1) short-term plasticity, that occurs in the milliseconds to minutes range, and includes the modulation of neurotransmitter release, and depends 
on post-translational modifications via phosphorylation, ubiquitination, and several other molecular processes (Bliss and Collingridge, 1993; Martin et al., 2000); (2) long-term plasticity, such as long-term potentiation (LTP) and depression (LTD), which may last from hours to months and is represented by cellular changes involving modification of the cellular protein repertoire that may require changes in transcriptional activity and are strictly dependent on protein synthesis (Martin et al., 2000); (3) homeostatic plasticity, which is the result of a variety of molecular and cellular events that shape neuronal circuits, continuously occurs in parallel with other plasticity phenomena and is thought to prevent runaway of neural activity by excessive excitation (Turrigiano, 2011).

Various studies have shown that disruptions of circadian rhythms alter synaptic plasticity and thus, learning and memory, including spatial and place learning and trace fear memory (Winocur and Hasher, 2004; Van der Zee et al., 2008; Wang et al., 2009; Jilg et al., 2010; Kondratova et al., 2010). Based on these studies, it has been suggested that a functional circadian clock is required for optimal learning and memory formation and consolidation (Becker-Weimann et al., 2004; Eckel-Mahan and Storm, 2009). The neural correlates and the mechanisms underpinning these clocks remain largely unknown. In the past two decades, the notion that brain function exclusively relies on neuronal signaling has been challenged by evidence that glial cells work in coordination with neurons, to regulate neurotransmission (Araque et al., 1999). These regulatory events occur through a set of molecular mechanisms that control neurotransmitter recycling (Danbolt et al., 2016), energy requirements (Newman et al., 2011; Suzuki et al., 2011), and eventually sleep homeostasis (Halassa et al., 2009b). This often involves, but is not limited to, the secretion of neuroactive molecules (or "gliotransmitters") in an activitydependent manner which target synaptic terminals modulating synaptic transmission (Bergles et al., 1997; Haydon, 2001; Lin and Bergles, 2004; Fellin et al., 2006; Perea et al., 2009).

Interestingly, astrocytes which are the most common glial cells in the cortex, have also been implicated in the circadian control of synaptic plasticity (Lavialle and Servière, 1993; Du et al., 2005; Lavialle et al., 2011; Hayashi et al., 2013a,b), suggesting a possible non-neuronal, glial candidate for the regulation of circadian rhythms that control learning and memory processes. This review focuses on this hypothesis, further elaborating on the possible clinical implications associated with disruptions of glialmediated pathways on circadian rhythms related to high brain function.

\section{CIRCADIAN CLOCKS AND THEIR MOLECULAR/GENETIC BASES}

Mammalian circadian clocks are hierarchically organized by a "master clock" in the suprachiasmatic nucleus (SCN) of the anterior hypothalamus. This clock coordinates independent peripheral clocks (Reppert and Weaver, 2002; Lowrey and Takahashi, 2004). At the molecular level, all of these clocks are the result of a translation-based, interconnected feedback loops in which the transcription factors Brain and Muscle ARNT-Like Protein 1 (BMAL1) and Circadian Locomotor Output Cycles Kaput (CLOCK) form heterodimers that regulate the circadian expression of Cryptochrome (Cry) and Period (Per; Dunlap, 1999; Reppert and Weaver, 2001), whose products lead to the inhibition of their own transcription. Additionally, an accessory regulatory loop involves the regulation of Bmal1 transcription by the coordinated action of the orphan nuclear receptors Reverse erb $\alpha$ (Rev-erb $\alpha$, repressor) and Retinoid-related orphan receptor$\alpha$ (Ror $\alpha$, activator) through the binding to the evolutionarily conserved nucleotide sequence $[\mathrm{A} / \mathrm{T}] \mathrm{A}[\mathrm{A} / \mathrm{T}] \mathrm{NT}[\mathrm{A} / \mathrm{G}] \mathrm{GGTCA}$ present in the promoter region of Bmal1 (Dunlap, 1999; Harmer et al., 2001; Reppert and Weaver, 2001; Preitner et al., 2002).

Significantly, a large number of circadian transcription factors not only regulate their own transcription, but also the expression of numerous other "clock-controlled genes" (CCGs) (Dunlap, 1999; Reppert and Weaver, 2001) whose protein products are not essential for the core clock mechanism itself. Among the genes that are part of the CCGs, various enzymes are included, like phosphoenolpyruvate carboxykinase, glycogen phosphorylase, and glucose-6-phosphatase (Panda et al., 2002); ion channels, like cGMP-gated cation channels, various voltage-gated calcium and potassium channels, the $\mathrm{Na}^{+} / \mathrm{K}^{+}$-ATPase, and a longopening cation channel (Ko et al., 2009); peptides, such as arginine-vasopressin (Avp; Jin et al., 1999) and D elementbinding protein (DBP; Le Martelot et al., 2009). In fact, cells rhythmically synthesize about $10 \%$ of their transcripts, including those involved in neuronal signaling and synaptic plasticity (Panda et al., 2002; Lowrey and Takahashi, 2004).

\section{CIRCADIAN CLOCKS, SLEEP, AND THEIR INVOLVEMENT IN SYNAPTIC PLASTICITY}

In recent years, numerous reports of in vitro and in vivo studies, have suggested an essential functional role of sleep in synaptic plasticity (Frank, 2011; Fellin et al., 2012). Accordingly, sleep has been proposed to strengthen, stabilize, or weaken synapses (Benington and Frank, 2003; Frank and Benington, 2006; Frank and Cantera, 2014). The molecular basis of these synaptic changes and whether sleep is necessary for their occurrence remain largely unknown. While sleep is the result of a combination of circadian rhythms and homeostatic mechanisms (Frank and Cantera, 2014), a clear causal connection between circadian clocks, sleep homeostasis, and synaptic plasticity has not been demonstrated.

In this context, it is noteworthy that the recycling of glutamate (Glu) is regulated by clock components, strongly suggesting a functional interplay between circadian rhythms and excitatory synaptic transmission (Beaulé et al., 2009). In fact, glial glutamate transporters are regulated by clock genes having a significant impact in the dynamic, activity-dependent metabolic coupling of glial cells with glutamatergic neurons. This glia/neuron interplay is mediated by the glutamate/glutamine cycle and the astrocyte/neuron/lactate shuttle (Martínez-Lozada and Ortega, 2015). In the same vein, taking into consideration the major role of Glu as the most abundant excitatory transmitter and its 
role in the molecular models of synaptic plasticity, like LTP and LTD, it is tempting to speculate that another molecular loop between clock genes' expression and glia/neuron coupling via the glutamatergic tripartite synapses control synaptic plasticity at the immediate, mediate and long-term ranges (Flores-Méndez et al., 2016).

\section{GLIAL REGULATION OF SYNAPTIC PLASTICITY}

\section{Astrocytes}

Beyond their recognized role in synapse development and neurodegeneration, astrocytes provide a delicate ensheathment of synapses in the mature brain (Chao et al., 2002; Theodosis et al., 2008). It is well-established that the degree of astrocytic ensheathing greatly changes with the brain area, hinting local specialization. In the hippocampus for example, a single astrocyte is in close proximity to few hundreds dendrites of different neurons, but can ensheathe up to several hundred thousands synapses (Bushong et al., 2002; Halassa et al., 2007; Agulhon et al., 2008). Such morphological arrangement provides the structural substrate for tight functional interactions between astrocytes and neurons (Saab et al., 2012; Bernardinelli et al., 2014).

Astrocytes are also recognized for their role in clearance of neurotransmitters, such as Glu and gamma-aminobutyric acid (GABA), from the synaptic cleft. Perisynaptic astrocytes processes are indeed enriched in transporters that guarantee rapid and efficient removal of the released neurotransmitters (Anderson and Swanson, 2000; Conti et al., 2004). Interestingly, the regulation of the kinetics and the extent of neurotransmitter clearance by astrocytes have been related to synaptic plasticity insofar as they both affect the degree of postsynaptic activation and desensitization (Tzingounis and Wadiche, 2007). Moreover, through the release of a variety of neuroactive molecules, such as Glu, D-serine, adenosine triphosphate (ATP), adenosine, GABA, tumor necrosis factor- $\alpha$ (TNF $\alpha$ ), prostaglandins, proteins and peptides, astrocytes are capable of regulating synaptic transmission and plasticity (Halassa and Haydon, 2010; Araque et al., 2014). These neuroactive molecules activate extrasynaptic metabotropic and ionotropic receptors, modifying neurotransmitter release and regulating short-term plasticity and synaptic efficacy (Parpura et al., 1994; Araque et al., 1998a,b, 2014; Halassa et al., 2009a; Halassa and Haydon, 2010).

Increasing evidence indicates that astrocytes could be involved in the synchronization of cortical firing. Cortical circuits for sensory integration are known to display transient synchrony of neuronal ensembles (Harris et al., 2003; Haider and McCormick, 2009). The hallmark of this synchronized activity is the alternation of UP states-i.e., episodes of persistent neuronal firing lasting few milliseconds - and DOWN states-i.e., episodes of neuronal hyperpolarization (Steriade et al., 2001; Brecht and Sakmann, 2002; Cossart et al., 2003; Kenet et al., 2003). UP and DOWN states are common in a wide range of conditions, including quiescent wakefulness (Gentet et al., 2010), anesthesia (Steriade et al., 1993; Ramaswamy and Muller, 2015), and sleep itself (Massimini and Amzica, 2001). Moreover, astrocytes have been implicated in UP state genesis through the release of Dserine, adenosine and ATP (Fellin et al., 2009, 2012; Halassa et al., 2009b; Poskanzer and Yuste, 2011, 2016). Interestingly, gliotransmission has been proposed to operate on different time scales (Fellin et al., 2012). According to the Hill and Tononi's model of sleep and in agreement with the modulation cortical UP and DOWN states, Fellin and colleagues have demonstrated that the depolarizing effect of NMDA receptors currents preserves the UP state (Hill and Tononi, 2004; Fellin et al., 2012). Such a role for NMDA receptors is thought to be dependent on the availability of glia-released D-serine (Fellin et al., 2012), again demonstrating a prominent role of glia/neuron coupling.

\section{Oligodendrocytes}

Oligodendrocytes projections wrap neuronal axons forming the myelin sheaths in the central nervous system (CNS). These myelin sheaths insulate the fibers, and help them to carry the nerve impulses. Interestingly, myelin can influence conduction velocity of the electrical impulse by regulating the axon diameter, thickness of the myelin sheath, the number and spacing of nodes of Ranvier, and nodal structure and molecular composition of ion channels in the node and paranodal region (Berthold et al., 1983; Wurtz and Ellisman, 1986; Baker and Stryker, 1990; Carr and Konishi, 1990; Dupree et al., 2004). Taking this into a consideration, it has been shown that myelin specific proteins, including Nogo-A (Chen et al., 2000; GrandPré et al., 2000), myelin-associated glycoprotein (MAG; McKerracher et al., 1994) and oligodendrocyte-myelin glycoprotein (OMgp; Wang et al., 2002; Huang et al., 2005), inhibit directly axon sprouting and synaptogenesis and constrain nervous system plasticity. This finding indicates the participation of myelin in learning, memory, and cognition.

\section{Microglia}

These glial cells are part of the brain's immune system and are mainly involved in the phagocytosis of foreign matter and cellular wastes of the CNS (Aloisi, 2001). Moreover, during postnatal development and adaptation to novel environments, microglia has a critical role in synaptic remodeling through the elimination of synapses and axon terminals. Additionally, increasing evidence points out that microglia could regulate synaptic plasticity and neurotransmission through the release of gliotransmitters (Batchelor et al., 1999, 2002; Zhong et al., 2010; Harry and Kraft, 2012; Sierra et al., 2013), as well as an increase hippocampal LTP and NMDA receptor-mediated responses via the secretion of glycine (Thomson et al., 1989; Abe et al., 1990; Hayashi et al., 2006). During neuroinflammation, microglia is capable to regulate excitatory neurotransmission by the rapid production of small amounts of ATP, that in turn, recruit astrocytes to augment ATP formation and Glu exocytosis enhancing synaptic transmission via metabotropic Glu receptors (Pascual et al., 2012). In fact, several reports reveal that some of the established astrocytic functions are regulated by the upstream activation of microglia (Ben Achour and Pascual, 2010; Pascual et al., 2012). 


\section{CIRCADIAN MODULATION OF THE SYNAPTIC PLASTICITY IN GLIAL CELLS}

Since 1978, it has been demonstrated that diverse cognitive processes are regulated by the circadian clocks in a phase-specific manner (Monk and Folkard, 1978). Particularly, in long-term memories generated in diverse learning paradigms, a role for the endogenous circadian clock has been reported both in vertebrates and invertebrates (Rudy and Pugh, 1998; Valentinuzzi et al., 2004; Rawashdeh et al., 2007). However, the circadian modulation of short-term memory formation has been almost impossible to prove. In this section, we summarize the evidence that involves different glial cells in processes of synaptic plasticity regulated by circadian generators.

\section{Astrocytes}

Gliotransmission is the process by which astrocytes interact with nearby neurons via the release of transmitters, like ATP and Glu (Haydon, 2001; Perea et al., 2009; Parpura and Zorec, 2010). Remarkably, ATP has been linked to modulation of LTP but also of synaptic depression (Gordon et al., 2005; Pascual et al., 2005; Bains and Oliet, 2007). In vivo, an astrocyte-dependent rhythmic ATP release is present in the SCN. Although the mechanisms responsible for these ATP oscillations are unknown, calcium-dependent signaling seems to be involved (Womac et al., 2009). Subsequently, it was shown that astrocytes display daily extracellular ATP oscillations that depend on the clock genes (Clock, Per, and Bmal1) and in inositol triphosphate $\left(\mathrm{IP}_{3}\right)$ signaling, indicating that extracellular ATP levels increase at a specific time of day and suggest a clock-induced increase in energy metabolism and glial activity, which participate in sleepwake changes in the brain and in control synaptic transmission (Marpegan et al., 2011).

To date, there is no report demonstrating that the circadian clock regulates Glu release. In contrast, accumulating evidence indicates that the glutamate/aspartate transporter (Glast) gene expression and protein levels exhibit a diurnal rhythm in a light/dark 12/12 h cycle (Spanagel et al., 2005). These findings are consistent with the absence of rhythmicity of GLAST in the Per2 mutant mice, pointing out the presence of a circadian control (Spanagel et al., 2005). Later on, using cultured cortical astrocytes from Clock mutant animals, it was observed a marked decrease in Glast mRNA and protein levels, proposing that glial Glu uptake activity is a function of the clock genes: Clock, Npas2, and Per2 (Beaulé et al., 2009). Specifically, the dependence related to CLOCK and NPAS2 may be due to their involvement in Glast transcription, or in GLAST stability and/or localization (Danbolt, 2001). It is important to mention that no conclusive evidence has been shown for a circadian-dependent change in Glu uptake, suggesting a non-circadian role for clock proteins in Glast transcription or Glast mRNA translation and/or stability (Beaulé et al., 2009). However, it is clear that the regulation and precise function of this transporter is very important to guarantee an efficient glutamatergic neurotransmission. A failure in synaptic Glu clearance is neurotoxic due to a hyperactivation of postsynaptic Glu receptors resulting in the phenomena known as excitotoxicity, which is implicated in most of neurodegenerative diseases (McEntee and Crook, 1993; Domingues et al., 2010; Gegelashvili and Bjerrum, 2014).

In the adult brain, the distribution of the specific astrocyte marker, glial fibrillary acidic protein (GFAP), has been reported to peak during daily rhythms in the SCN (Lavialle and Servière, 1993). Furthermore, it has been demonstrated that this peak also prevails in constant darkness (Lavialle and Servière, 1993; Moriya et al., 2000), strongly suggesting that these rhythms are essential and independent of environmental light. Although the function of circadian fluctuations of GFAP immunoreactivity is unknown, it has been observed that mice lacking the gfap gene show reduced eyeblink training and impaired LTD in the cerebellum (Shibuki et al., 1996), suggesting that this protein plays a role in the regulation of neuronal functions.

CNS excitatory synapses are extremely dynamic structures that show stabilization in response to learning and memory process. These synapses are surrounded by intricate astrocytic processes denominated perisynaptic astrocytic processes (PAPs; Iino et al., 2001; Hirrlinger et al., 2004; Nishida and Okabe, 2007). It has been described in primary cultured astrocytes that ezrin (an actin-binding protein) is required for filopodia formation and motility of PAPs, such motility can be induced by Glu via activation of metabotropic Glu receptors 3 and 5 (Lavialle et al., 2011). Moreover, changes in glutamatergic circadian activity in the hamster SCN are in synchrony with changes in ezrin immunoreactivity which is consistent with Glu-induced perisynaptic glial motility (Lavialle et al., 2011). These results suggest that ezrin is essential for Glu-induced PAPs plasticity that could be regulated by circadian system.

On the other hand, the brain fatty-acid binding protein (FABP7) localizes in astrocytes and neuronal cell precursors in the mature brain, and presents a high binding affinity to long chain fatty acids whose effects on brain function include development, emotion, learning, and memory (Yamamoto et al., 1987; Jensen et al., 1996; Wainwright et al., 1997; Moriguchi et al., 2000; Takeuchi et al., 2003). Gerstner and colleagues demonstrated in adult murine brain that levels of Fabp7 mRNA oscillate over a $24 \mathrm{~h}$ period in brain areas that participate in daily activity and sleep like the hypothalamus, the tuberomammilary nucleus, the pons and the locus coeruleus. In these areas, Fabp7 diminish in the dark phase and increase instead in the light phase (Gerstner et al., 2006, 2008). In contrast with its mRNA levels, FABP7 levels are higher during the dark phase (Gerstner et al., 2008), indicating that expression of this protein is delayed by $12 \mathrm{~h}$ with regards to its mRNA. More recently, the same group demonstrated that FABP7 is specifically augmented in the perisynaptic compartment of fine astrocytic processes that surround synapses. Furthermore, CPEB-mediated cytoplasmic polyadenylation controls the diurnally regulated Fabp7 mRNA levels (Gerstner et al., 2012). Accordingly, in plasticity terms, targeting of Fabp7 and CPEB-mediated polyadenylation could participate in controlling astrocytic process extension, although it is unknown if variations in synaptic plasticity and/or neuronal activity modify polyadenylation and trafficking of Fabp7 mRNA resulting in morphological modifications of the astrocytic processes (Gerstner et al., 2012). In addition, variations in cycle-dependent memory formation and synaptic plasticity could 
regulate the circadian variations in subcellular trafficking and localization of Fabp7 mRNA in hippocampal tripartite synapses (Gerstner et al., 2009, 2012).

\section{Oligodendrocytes}

To date, there is no evidence that oligodendrocytes have an internal circadian clock; however, it has been reported that oligodendrocytes precursor cells (OPCs) proliferation in the hippocampus could be regulated by clock genes (Matsumoto et al., 2011). It should be noted that OPCs proliferation itself could modulate the synaptic plasticity of the hippocampus in response to neuronal activity, thus circadian proliferation of these cells could regulate hippocampal function. Particularly, the OPCs give rise to mature oligodendrocytes, and are thought to be a constitutive reservoir of oligodendrocytes that replace damaged myelin (Levine et al., 1993) or add de novo myelination (McCarthy and Leblond, 1988). Interestingly, myelin proteolipid protein $(p l p)$, a myelin-specific gene, is regulated by Clock (Du et al., 2005), suggesting that the circadian clock controls myelin formation.

\section{Microglia}

Microglial cells constantly retract and extend their processes to sense their local environment contributing to the maintenance of healthy neuronal circuits (Kirchhoff, 2013). There is evidence that an intrinsic molecular clock exists in cortical microglia which controls diurnal morphological changes of its processes, and whereby these cells regulate the sleep-wake cycle-dependent changes in synaptic strength (Hayashi et al., 2013a,b). In line with these findings, it has been reported that the microgliaspecific lysosomal cysteine protease Cathepsin S (CatS) exhibits a circadian expression in cortical microglia. The expression of CatS is involved in diurnal variations of synaptic strength in cortical neurons via the proteolytic modification of the perineuronal environment. However, disruptions in CatS lead to hyperlocomotor activity and to the deletion of the diurnal variations in spine density and synaptic activity of these cortical neurons as a consequence of the failure to downscale synaptic strength during sleep (Hayashi et al., 2013a). Since downscaling of synaptic strength is required for the acquisition and consolidation of novel information upon awakening, it is evident that dysfunction of the microglial intrinsic circadian clock is involved in neuropsychiatric disorders based on sleep disturbance, including depression and cognitive impairment (Bhattacharjee, 2007; Hayashi et al., 2014).

On the other hand, microglial cells express ATP receptors of the P2X (P2XR, ligand-gated ion-channel receptor) and P2Y subtypes (P2YR, G protein-coupled receptor). ATP released by glial cells during neuronal activity is then, capable to influence synaptic transmission. In fact in microglial cells, ATP increases the number their branch points, extension of their processes and morphological complexity (Fontainhas et al., 2011). Specifically, it has been demonstrated that the degree of microglial process extension is controlled by microglial $\mathrm{P}_{2} \mathrm{Y}_{12} \mathrm{Rs}$ (Haynes et al., 2006). Moreover, Hayashi and colleagues reported that microglial $\mathrm{P}_{2} \mathrm{Y}_{12}$ Rs present circadian oscillations regardless that microglia would be isolated under constant darkness conditions (Hayashi et al., 2013b). Interestingly, inhibition of these purinergic receptors disrupts the rhythmic patterns of synaptic strength or spine density, while upregulated $\mathrm{P}_{2} \mathrm{Y}_{12}$ Rs during the dark phase results in extension of the microglial processes that are partially retracted during the light phase resulting in a decrease of synaptic strength or spine density (Hayashi et al., 2013b). In the same fashion of CatS disruptions, dysfunctions in microgliasynapse interactions participate in neuropsychiatric disorders (Bhattacharjee, 2007; Hayashi et al., 2014).

Concerning P2X purinergic receptors, Nakazato and coworkers demonstrated that ATP selectively promotes the expression of the protein and mRNA of Perl through the activation of P2X7R in microglial cells (Nakazato et al., 2011). While the outcome of this upregulation is not completely clear, it has been reported that Per is not only crucial for long-term memory formation (LTM), but overexpression of this gene also enhances memory formation (Sakai et al., 2004). Taken together these evidences suggest that Per has an important function in the regulation of circadian synaptic plasticity in microglia.

Additionally, several reports indicate that ATP promotes microglial cells to secrete several signaling molecules, like interleukin-1 beta (IL-1 $\beta$ ), TNF $\alpha$, and plasminogen (Inoue et al., 1998; Hide et al., 2000; Sanz and Di Virgilio, 2000; Suzuki et al., 2004); which are involved in the modulation of synaptic transmission and plasticity (Ikegaya et al., 2003; Becker et al., 2013; Liu et al., 2014). Finally, it should be noted that microglia display rhythmic fluctuations in the gene expression of these mediators (Fonken et al., 2015).

\section{CLINICAL IMPLICATIONS}

Although synaptic dysfunction is the cellular basis of most mental illnesses, disturbance of the circadian clock system and dysfunctions of glial cells are likely to be involved in diverse brain pathologies. Up to now, only few studies, summarized in Table 1, provide a link between brain disorders, circadian rhythm dysfunction and glial physiology. For example, a study using Per $2^{\text {Brdm } 1}$ mutant mice demonstrated that a nonfunctional Per2 results in a hyperglutamatergic state due to a reduced GLAST expression and as a consequence, Glu uptake by astrocyte is diminished (Spanagel et al., 2005). Accordingly, one could expect that a reduction of astrocytic Glu uptake would be related to severe pathophysiological implications as shown in several disease models, including multiple sclerosis, Alzheimer's, and Huntington diseases (Domingues et al., 2010). Additionally, several studies related to proteins that are involved in the regulation of the astrocytic processes extension that surround synapses, like ezrin and FABP7, have shown that dysfunctions in these proteins lead to impairment in processes, like development, learning, memory, and emotion (Lavialle et al., 2011; Gerstner et al., 2012).

The fact that microglia exhibits circadian rhythmicity, such as oscillating expression patterns of clock genes that regulate the expression of $\mathrm{P}_{2} \mathrm{Y}_{12} \mathrm{R}$ and of the CatS protease suggests that alteration of these two factors disrupts the rhythmic patterns of synaptic strength and spine density (Hayashi et al., 2013a,b). 
TABLE 1 | Clock-controlled genes (CCG) and their implications in brain pathologies.

\begin{tabular}{|c|c|c|c|}
\hline CCG & Preparation & Pathological implications & References \\
\hline \multicolumn{4}{|c|}{ ASTROCYTES } \\
\hline ATP & $\begin{array}{l}\text { Cortical } \\
\text { astrocyte } \\
\text { cultures }\end{array}$ & $\begin{array}{l}\text { Disruptions in sleep-wake } \\
\text { changes in the brain and in } \\
\text { control synaptic transmission. }\end{array}$ & $\begin{array}{l}\text { Marpegan et al. } \\
2011\end{array}$ \\
\hline GLAST & $\begin{array}{l}\text { Per2 mutant } \\
\text { mice }\end{array}$ & $\begin{array}{l}\text { Dysregulation in the Glu uptake } \\
\text { process. }\end{array}$ & $\begin{array}{l}\text { Spanagel et al., } \\
2005\end{array}$ \\
\hline GFAP & $\begin{array}{l}\text { GFAP mutant } \\
\text { mice }\end{array}$ & $\begin{array}{l}\text { Impaired LTD in the cerebellum, } \\
\text { as well as reduced eyeblink } \\
\text { conditioning. }\end{array}$ & $\begin{array}{l}\text { Shibuki et al., } \\
1996\end{array}$ \\
\hline Ezrin & $\begin{array}{l}\text { Primary } \\
\text { astrocytes } \\
\text { cultures }\end{array}$ & $\begin{array}{l}\text { Alterations in the Glu-induced } \\
\text { PAPs plasticity. }\end{array}$ & $\begin{array}{l}\text { Lavialle et al., } \\
2011\end{array}$ \\
\hline FABP7 & $\begin{array}{l}\text { Primary mouse } \\
\text { astrocyte culture }\end{array}$ & $\begin{array}{l}\text { Dysregulation of astrocytic } \\
\text { processes extension. }\end{array}$ & $\begin{array}{l}\text { Gerstner et al., } \\
2012\end{array}$ \\
\hline \multicolumn{4}{|c|}{ OLIGODENDROCYTES } \\
\hline OPCs & $\begin{array}{l}\text { Mouse } \\
\text { hippocampus } \\
\text { slices }\end{array}$ & $\begin{array}{l}\text { Alterations in synaptic plasticity } \\
\text { for the hippocampal function. }\end{array}$ & $\begin{array}{l}\text { Matsumoto } \\
\text { et al., } 2011\end{array}$ \\
\hline \multicolumn{4}{|c|}{ MICROGLIA } \\
\hline CatS & CatS $^{-/-}$mice & $\begin{array}{l}\text { Neurological disorders by } \\
\text { disruption of the circadian } \\
\text { oscillation patterns of synaptic } \\
\text { strength and spine density in } \\
\text { cortical neurons. }\end{array}$ & $\begin{array}{l}\text { Hayashi et al., } \\
2013 a\end{array}$ \\
\hline $\mathrm{P}_{2} \mathrm{Y}_{12} \mathrm{R}$ & $\begin{array}{l}\text { Cortical } \\
\text { microglia } \\
\text { cultures }\end{array}$ & $\begin{array}{l}\text { Neurological disorders by } \\
\text { disruption of the rhythmic } \\
\text { patterns of synaptic strength or } \\
\text { spine density. }\end{array}$ & $\begin{array}{l}\text { Hayashi et al., } \\
\text { 2013b }\end{array}$ \\
\hline \multirow[t]{2}{*}{ P2X7R } & $\begin{array}{l}\text { Cultured murine } \\
\text { microglia and } \\
\text { BV-2 cells }\end{array}$ & $\begin{array}{l}\text { Downregulates Per1 mRNA } \\
\text { expression. }\end{array}$ & $\begin{array}{l}\text { Nakazato et al., } \\
2011\end{array}$ \\
\hline & & $\begin{array}{l}\text { Reduces the number of } \\
\text { processes in microglial cells as a } \\
\text { result of cellular activation. }\end{array}$ & \\
\hline
\end{tabular}

ATP, Adenosine triphosphate; CatS, cathepsin S; FABP7, brain-type fatty acid binding protein; GFAP, glial fibrillary acidic protein; GLAST, Glu/aspartate transporter; LTD, long-term depression; OPCs, oligodendrocytes precursor cells; P2X7R, P2X7 receptor; $P 2 Y_{12} R, P 2 Y_{12}$ receptor; PAPs, perisynaptic astrocytic processes.

In this context, healthy brain synaptic homeostasis depends on microglia-synapse interactions controlled by the intrinsic microglial clock, so the dysfunction of this clock most probably leads to neuropsychiatric disorders, like depression and cognitive deficits (Bhattacharjee, 2007; Hayashi et al., 2014).

Finally, it has been demonstrated that sleep disturbances are involved with multiple negative effects on human physiology, including neuronal dysfunction (Joo et al., 2013), mood disturbances (Dinges et al., 1997), cognitive impairments (Lo et al., 2012), and disruption to circadian rhythmicity (MöllerLevet et al., 2013).

\section{CONCLUSIONS}

Glial cells have long been regarded as simple supportive cells of neuronal function. However, in recent years, several reports have demonstrated the involvement glial cells in diverse processes required for proper brain function, including contribution to the regulation of the synaptic plasticity. Taking into consideration that clock genes modify glial Glu transporters and, by these means, control the strength and continuity of the major excitatory system, their role in higher brain functions is likely of a high relevance. Accordingly, specific alterations of the circadian system are related to various diseases in which glutamatergic transmission is impaired. Additionally, dysfunction of astrocyteneuron signaling plays a critical role in the pathology of most of the neurodegenerative diseases, such as Alzheimer, Parkinson, and Huntington. Altogether, these findings make it clear that glial cells are an important tool to understand the circadian regulation of synaptic plasticity, both in the short and in the long terms. Certainly, characterization of the activity-dependent and clockdependent changes in glial proteins repertoire will provide a major input to our understanding of the pivotal role of glial cells in higher brain functions.

\section{AUTHOR CONTRIBUTIONS}

DC-C gathered the relevant information, wrote the manuscript, as well as elaborated the table. AO reviewed and edited the final version of the manuscript.

\section{FUNDING}

The work in the lab is supported by grants from Conacyt-México (255087) and "Soluciones para un México Verde S.A. de C.V." to AO; DC-C is supported by SNI-Conacyt.

\section{REFERENCES}

Abe, K., Xie, F. J., Watanabe, Y., and Saito, H. (1990). Glycine facilitates induction of long-term potentiation of evoked potential in rat hippocampus. Neurosci. Lett. 117, 87-92. doi: 10.1016/0304-3940(90) 90124-R

Agulhon, C., Petravicz, J., McMullen, A. B., Sweger, E. J., Minton, S. K., Taves, S. R., et al. (2008). What is the role of astrocyte calcium in neurophysiology? Neuron 59, 932-946. doi: 10.1016/j.neuron.2008. 09.004

Aloisi, F. (2001). Immune function of microglia. Glia 36, 165-179. doi: $10.1002 /$ glia.1106

Anderson, C. M., and Swanson, R. A. (2000). Astrocyte glutamate transport: review of properties, regulation, and physiological functions. Glia 32, 1-14. doi: 10.1002/1098-1136(200010)32:1\&lt;1::AID-GLIA10\&gt;3.0.CO;2-W

Araque, A., Carmignoto, G., Haydon, P. G., Oliet, S. H., Robitaille, R., and Volterra, A. (2014). Gliotransmitters travel in time and space. Neuron 81, 728-739. doi: 10.1016/j.neuron.2014.02.007

Araque, A., Parpura, V., Sanzgiri, R. P., and Haydon, P. G. (1998a). Glutamatedependent astrocyte modulation of synaptic transmission between cultured hippocampal neurons. Eur. J. Neurosci. 10, 2129-2142.

Araque, A., Parpura, V., Sanzgiri, R. P., and Haydon, P. G. (1999). Tripartite synapses: glia, the unacknowledged partner. Trends Neurosci. 22, 208-215. doi: 10.1016/S0166-2236(98)01349-6 
Araque, A., Sanzgiri, R. P., Parpura, V., and Haydon, P. G. (1998b). Calcium elevation in astrocytes causes an NMDA receptor-dependent increase in the frequency of miniature synaptic currents in cultured hippocampal neurons. J. Neurosci. 18, 6822-6829.

Bains, J. S., and Oliet, S. H. R. (2007). Glia: they make your memories stick! Trends Neurosci. 30, 417-424. doi: 10.1016/j.tins.2007.06.007

Baker, G. E., and Stryker, M. P. (1990). Retinofugal fibres change conduction velocity and diameter between the optic nerve and tract in ferrets. Nature 344, 342-345. doi: 10.1038/344342a0

Batchelor, P. E., Liberatore, G. T., Wong, J. Y., Porritt, M. J., Frerichs, F., Donnan, G. A., et al. (1999). Activated macrophages and microglia induce dopaminergic sprouting in the injured striatum and express brain-derived neurotrophic factor and glial cell line-derived neurotrophic factor. J. Neurosci. 19, 1708-1716.

Batchelor, P. E., Porritt, M. J., Martinello, P., Parish, C. L., Liberatore, G. T., Donnan, G. A., et al. (2002). Macrophages and microglia produce local trophic gradients that stimulate axonal sprouting toward but not beyond the wound edge. Mol. Cell. Neurosci. 21, 436-453. doi: 10.1006/mcne.2002.1185

Beaulé, C., Swanstrom, A., Leone, M. J., and Herzog, E. D. (2009). Circadian modulation of gene expression, but not glutamate uptake, in mouse and rat cortical astrocytes. PLoS ONE 4:e7476. doi: 10.1371/journal.pone.0007476

Becker, D., Zahn, N., Deller, T., and Vlachos, A. (2013). Tumor necrosis factor alpha maintains denervation-induced homeostatic synaptic plasticity of mouse dentate granule cells. Front. Cell. Neurosci. 7:257. doi: 10.3389/fncel.2013.00257

Becker-Weimann, S., Wolf, J., Herzel, H., and Kramer, A. (2004). Modeling feedback loops of the mammalian circadian oscillator. Biophys. J. 87, 3023-3034. doi: 10.1529/biophysj.104.040824

Ben Achour, S., and Pascual, O. (2010). Glia: the many ways to modulate synaptic plasticity. Neurochem. Int. 57, 440-445. doi: 10.1016/j.neuint.2010.02.013

Benington, J. H., and Frank, M. G. (2003). Cellular and molecular connections between sleep and synaptic plasticity. Prog. Neurobiol. 69, 71-101. doi: 10.1016/S0301-0082(03)00018-2

Bergles, D. E., Dzubay, J. A., and Jahr, C. E. (1997). Glutamate transporter currents in Bergmann glial cells follow the time course of extrasynaptic glutamate. Proc. Natl. Acad. Sci. U.S.A. 94, 14821-14825. doi: 10.1073/pnas.94.26.14821

Bernardinelli, Y., Muller, D., and Nikonenko, I. (2014). Astrocyte-synapse structural plasticity. Neural Plast. 2014, 1-13. doi: 10.1155/2014/232105

Berthold, C. H., Nilsson, I., and Rydmark, M. (1983). Axon diameter and myelin sheath thickness in nerve fibres of the ventral spinal root of the seventh lumbar nerve of the adult and developing cat. J. Anat. 136, 483-508.

Bhattacharjee, Y. (2007). Is internal timing key to mental health? Science 317, 1488-1490. doi: 10.1126/science.317.5844.1488

Bliss, T. V., and Collingridge, G. L. (1993). A synaptic model of memory: long-term potentiation in the hippocampus. Nature 361, 31-39. doi: 10.1038/361031a0

Brecht, M., and Sakmann, B. (2002). Dynamic representation of whisker deflection by synaptic potentials in spiny stellate and pyramidal cells in the barrels and septa of layer 4 rat somatosensory cortex. J. Physiol. 543, 49-70. doi: 10.1113/jphysiol.2002.018465

Bushong, E. A., Martone, M. E., Jones, Y. Z., and Ellisman, M. H. (2002). Protoplasmic astrocytes in CA1 stratum radiatum occupy separate anatomical domains. J. Neurosci. 22, 183-192.

Carr, C. E., and Konishi, M. (1990). A circuit for detection of interaural time differences in the brain stem of the barn owl. J. Neurosci. 10, 3227-3246.

Chao, T. I., Rickmann, J. R., and Wolff, J. R. (2002). "The synapse-astrocyte boundary: An anatomical basis for an integrative role of glia in synaptic transmission," in The Tripartite Synapse: Glia in Synaptic Transmission, eds A. Volterra, P. J. Magistretti, and P. G. Haydon (Oxford: Oxford University Press), 3-23.

Chen, M. S., Huber, A. B., van der Haar, M. E., Frank, M., Schnell, L., Spillmann, A. A., et al. (2000). Nogo-A is a myelin-associated neurite outgrowth inhibitor and an antigen for monoclonal antibody IN-1. Nature 403, 434-439. doi: $10.1038 / 35000219$

Conti, F., Minelli, A., and Melone, M. (2004). GABA transporters in the mammalian cerebral cortex: localization, development and pathological implications. Brain Res. Rev. 45, 196-212. doi: 10.1016/j.brainresrev.2004.03.003

Cossart, R., Aronov, D., and Yuste, R. (2003). Attractor dynamics of network UP states in the neocortex. Nature 423, 283-288. doi: 10.1038/nature01614
Danbolt, N. C. (2001). Glutamate uptake. Prog Neurobiol. 65, 1-105. doi: 10.1016/S0301-0082(00)00067-8

Danbolt, N. C., Furness, D. N., and Zhou, Y. (2016). Neuronal vs glial glutamate uptake: resolving the conundrum. Neurochem. Int. 98, 29-45. doi: 10.1016/j.neuint.2016.05.009

De Pittà, M., Brunel, N., and Volterra, A. (2016). Astrocytes: Orchestrating synaptic plasticity? Neuroscience 323, 43-61. doi: 10.1016/j.neuroscience.2015.04.001

Dinges, D. F., Pack, F., Williams, K., Gillen, K. A., Powell, J. W., Ott, G. E., et al. (1997). Cumulative sleepiness, mood disturbance, and psychomotor vigilance performance decrements during a week of sleep restricted to 4-5 hours per night. Sleep 20, 267-277.

Domingues, A. M., Taylor, M., and Fern, R. (2010). Glia as transmitter sources and sensors in health and disease. Neurochem. Int. 57, 359-366. doi: 10.1016/j.neuint.2010.03.024

Du, Y. Z., Fan, S. J., Meng, Q. H., Wang, G. Q., and Tong, J. (2005). Circadian expression of clock and screening of clock-controlled genes in peripheral lymphocytes of rat. Biochem. Biophys. Res. Commun. 336, 1069-1073. doi: $10.1016 /$ j.bbrc.2005.08.228

Dunlap, J. C. (1999). Molecular bases for circadian clocks. Cell 96, 271-290. doi: 10.1016/S0092-8674(00)80566-8

Dupree, J. L., Mason, J. L., Marcus, J. R., Stull, M., Levinson, R., Matsushima, G. K., et al. (2004). Oligodendrocytes assist in the maintenance of sodium channel clusters independent of the myelin sheath. Neuron Glia Biol. 1, 179-192. doi: $10.1017 / \mathrm{S} 1740925 \mathrm{X} 04000304$

Eckel-Mahan, K. L., and Storm, D. R. (2009). Circadian rhythms and memory: not so simple as cogs and gears. EMBO Rep. 10, 584-591. doi: 10.1038/embor.2009.123

Fellin, T., Ellenbogen, J. M., De Pittà, M., Ben-Jacob, E., and Halassa, M. M. (2012). Astrocyte regulation of sleep circuits: experimental and modeling perspectives. Front. Comput. Neurosci. 6:65. doi: 10.3389/fncom.2012.00065

Fellin, T., Halassa, M. M., Terunuma, M., Succol, F., Takano, H., Frank, M., et al. (2009). Endogenous nonneuronal modulators of synaptic transmission control cortical slow oscillations in vivo. Proc. Natl. Acad. Sci. U.S.A. 106, 15037-15042. doi: 10.1073/pnas.0906419106

Fellin, T., Pascual, O., and Haydon, P. G. (2006). Astrocytes coordinate synaptic networks: balanced excitation and inhibition. Physiology 21, 208-215. doi: 10.1152/physiol.00161.2005

Flores-Méndez, M., Mendez-Flores, O. G., and Ortega, A. (2016). Glia plasma membrane transporters: key players in glutamatergic neurotransmission. Neurochem. Int. 98, 46-55. doi: 10.1016/j.neuint.2016.04.004

Fonken, L. K., Frank, M. G., Kitt, M. M., Barrientos, R. M., Watkins, L. R., and Maier, S. F. (2015). Microglia inflammatory responses are controlled by an intrinsic circadian clock. Brain Behav. Immun. 45, 171-179. doi: 10.1016/j.bbi.2014.11.009

Fontainhas, A. M., Wang, M., Liang, K. J., Chen, S., Mettu, P., Damani, M., et al. (2011). Microglial morphology and dynamic behavior is regulated by ionotropic glutamatergic and GABAergic neurotransmission. PLoS ONE 6:e15973. doi: 10.1371/journal.pone.0015973

Frank, M. G. (2011). Sleep and developmental plasticity not just for kids. Prog. Brain Res. 193, 221-232. doi: 10.1016/B978-0-444-53839-0.00014-4

Frank, M. G., and Benington, J. H. (2006). The role of sleep in memory consolidation and brain plasticity: dream or reality? Neuroscience 12, 477-488. doi: $10.1177 / 1073858406293552$

Frank, M. G., and Cantera, R. (2014). Sleep, clocks, and synaptic plasticity. Trends Neurosci. 37, 491-501. doi: 10.1016/j.tins.2014.06.005

Gegelashvili, G., and Bjerrum, O. J. (2014). High-affinity glutamate transporters in chronic pain: an emerging therapeutic target. J. Neurochem. 131, 712-730. doi: 10.1111/jnc. 12957

Gentet, L. J., Avermann, M., Matyas, F., Staiger, J. F., and Petersen, C. C. H. (2010). Membrane potential dynamics of GABAergic neurons in the barrel cortex of behaving mice. Neuron 65, 422-435. doi: 10.1016/j.neuron.2010. 01.006

Gerstner, J. R., Bremer, Q. Z., Vander Heyden, W. M., LaVaute, T. M., Yin, J. C., and Landry, C. F. (2008). Brain fatty acid binding protein (Fabp7) is diurnally regulated in astrocytes and hippocampal granule cell precursors in adult rodent brain. PLoS ONE 3:e1631. doi: 10.1371/journal.pone.0001631 
Gerstner, J. R., Lyons, L. C., Wright, K. P., Loh, D. H., Rawashdeh, O., EckelMahan, K. L., et al. (2009). Cycling behavior and memory formation. J. Neurosci. 29, 12824-12830. doi: 10.1523/JNEUROSCI.3353-09.2009

Gerstner, J. R., Vander Heyden, W. M., LaVaute, T. M., and Landry, C. F. (2006). Profiles of novel diurnally regulated genes in mouse hypothalamus: expression analysis of the cysteine and histidine-rich domaincontaining, zinc-binding protein 1 , the fatty acid-binding protein 7 and the GTPase, ras-like family member 11b. Neuroscience 139, 1435-1448. doi: 10.1016/j.neuroscience.2006.01.020

Gerstner, J. R., Vanderheyden, W. M., LaVaute, T., Westmark, C. J., Rouhana, L., Pack, A. I., et al. (2012). Time of day regulates subcellular trafficking, tripartite synaptic localization, and polyadenylation of the astrocytic Fabp7 mRNA. J. Neurosci. 32, 1383-1394. doi: 10.1523/JNEUROSCI.3228-11.2012

Gordon, G. R., Baimoukhametova, D. V., Hewitt, S. A., Rajapaksha, W. R., Fisher, T. E., and Bains, J. S. (2005). Norepinephrine triggers release of glial ATP to increase postsynaptic efficacy. Nat. Neurosci. 8, 1078-1086. doi: $10.1038 / \mathrm{nn} 1498$

GrandPré, T., Nakamura, F., Vartanian, T., and Strittmatter, S. M. (2000). Identification of the Nogo inhibitor of axon regeneration as a Reticulon protein. Nature 403, 439-444. doi: $10.1038 / 35000226$

Haider, B., and McCormick, D. A. (2009). Rapid neocortical dynamics: cellular and network mechanisms. Neuron 62, 171-189. doi: 10.1016/j.neuron.2009.04.008

Halassa, M. M., Fellin, T., and Haydon, P. G. (2009a). Tripartite synapses: roles for astrocytic purines in the control of synaptic physiology and behavior. Neuropharmacology 57, 343-346. doi: 10.1016/j.neuropharm.2009.06.031

Halassa, M. M., Fellin, T., Takano, H., Dong, J.-H., and Haydon, P. G. (2007). Synaptic islands defined by the territory of a single astrocyte. J. Neurosci. 27, 6473-6477. doi: 10.1523/JNEUROSCI.1419-07.2007

Halassa, M. M., Florian, C., Fellin, T., Munoz, J. R., Lee, S.-Y., Abel, T., et al. (2009b). Astrocytic modulation of sleep homeostasis and cognitive consequences of sleep loss. Neuron 61, 213-219. doi: 10.1016/j.neuron.2008.11.024

Halassa, M. M., and Haydon, P. G. (2010). Integrated brain circuits: astrocytic networks modulate neuronal activity and behavior. Annu. Rev. Physiol. 72, 335-355. doi: 10.1146/annurev-physiol-021909-135843

Halberg, F. (1959). Physiologic 24-hour periodicity; general and procedural considerations with reference to the adrenal cycle. Int. Z. Vitaminforsch. Beih. $10,225-296$.

Harmer, S. L., Panda, S., and Kay, S. A. (2001). Molecular bases of circadian rhythms. Annu. Rev. Cell Dev. Biol. 17, 215-253. doi: 10.1146/annurev.cellbio.17.1.215

Harris, K. D., Csicsvari, J., Hirase, H., Dragoi, G., and Buzsáki, G. (2003). Organization of cell assemblies in the hippocampus. Nature 424, 552-556. doi: $10.1038 /$ nature 01834

Harry, G. J., and Kraft, A. D. (2012). Microglia in the developing brain: a potential target with lifetime effects. Neurotoxicology 33, 191-206. doi: 10.1016/j.neuro.2012.01.012

Hartse, K. M. (2011). "The phylogeny of sleep," in Handbook of Clinical Neurology, Vol. 98, eds P. Montagna and S. Chokroverty (Amsterdam: Elsevier), 97-109.

Hayashi, Y., Ishibashi, H., Hashimoto, K., and Nakanishi, H. (2006). Potentiation of the NMDA receptor-mediated responses through the activation of the glycine site by microglia secreting soluble factors. Glia 53, 660-668. doi: $10.1002 /$ glia.20322

Hayashi, Y., Koyanagi, S., Kusunose, N., Okada, R., Wu, Z., Tozaki-Saitoh, H., et al. (2013a). The intrinsic microglial molecular clock controls synaptic strength via the circadian expression of cathepsin S. Sci. Rep. 3:2744. doi:10.1038/srep02744

Hayashi, Y., Koyanagi, S., Kusunose, N., Takayama, F., Okada, R., Wu, Z., et al. (2013b). Diurnal spatial rearrangement of microglial processes through the rhythmic expression of P2Y12 receptors. J. Neurol. Disord. 1:120. doi: $10.4172 / 2329-6895.1000120$

Hayashi, Y., Wu, Z., and Nakanishi, H. (2014). A possible link between microglial process dysfunction and neuropsychiatric disorders. J. Neurol. Disord. Stroke 2:1060.

Haydon, P. G. (2001). GLIA: listening and talking to the synapse. Nat. Rev. Neurosci. 2, 185-193. doi: 10.1038/35058528

Haynes, S. E., Hollopeter, G., Yang, G., Kurpius, D., Dailey, M. E., Gan, W.-B., et al. (2006). The P2Y12 receptor regulates microglial activation by extracellular nucleotides. Nat. Neurosci. 9, 1512-1519. doi: 10.1038/nn1805
Hide, I., Tanaka, M., Inoue, A., Nakajima, K., Kohsaka, S., Inoue, K., et al. (2000). Extracellular ATP triggers tumor necrosis factor-alpha release from rat microglia. J. Neurochem. 75, 965-972. doi: 10.1046/j.1471-4159.2000. 0750965.x

Hill, S., and Tononi, G. (2004). Modeling sleep and wakefulness in the thalamocortical system. J. Neurophysiol. 93, 1671-1698. doi: 10.1152/jn.00915.2004

Hirrlinger, J., Hülsmann, S., and Kirchhoff, F. (2004). Astroglial processes show spontaneous motility at active synaptic terminals in situ. Eur. J. Neurosci. 20, 2235-2239. doi: 10.1111/j.1460-9568.2004.03689.x

Huang, J. K., Phillips, G. R., Roth, A. D., Pedraza, L., Shan, W., Belkaid, W., et al. (2005). Glial membranes at the node of Ranvier prevent neurite outgrowth. Science 310, 1813-1817. doi: 10.1126/science.1118313

Iino, M., Goto, K., Kakegawa, W., Okado, H., Sudo, M., Ishiuchi, S., et al. (2001). Glia-synapse interaction through Ca2+-permeable AMPA receptors in Bergmann glia. Science 292, 926-929. doi: 10.1126/science.1058827

Ikegaya, Y., Delcroix, I., Iwakura, Y., Matsuki, N., and Nishiyama, N. (2003). Interleukin-1beta abrogates long-term depression of hippocampal CA1 synaptic transmission. Synapse 47, 54-57. doi: 10.1002/syn.10154

Inoue, K., Nakajima, K., Morimoto, T., Kikuchi, Y., Koizumi, S., Illes, P., et al. (1998). ATP stimulation of Ca2+-dependent plasminogen release from cultured microglia. Br. J. Pharmacol. 123, 1304-1310. doi: $10.1038 /$ sj.bjp. 0701732

Jensen, C. L., Chen, H., Fraley, J. K., Anderson, R. E., and Heird, W. C. (1996). Biochemical effects of dietary linoleic/alpha-linolenic acid ratio in term infants. Lipids 31, 107-113. doi: 10.1007/BF02522419

Jilg, A., Lesny, S., Peruzki, N., Schwegler, H., Selbach, O., Dehghani, F., et al. (2010). Temporal dynamics of mouse hippocampal clock gene expression support memory processing. Hippocampus 20, 377-388. doi: 10.1002/hipo.20637

Jin, X., Shearman, L. P., Weaver, D. R., Zylka, M. J., de Vries, G. J., and Reppert, S. M. (1999). A molecular mechanism regulating rhythmic output from the suprachiasmatic circadian clock. Cell 96, 57-68. doi: 10.1016/S0092-8674(00)80959-9

Joo, E. Y., Noh, H. J., Kim, J.-S., Koo, D. L., Kim, D., Hwang, K. J., et al. (2013). Brain gray matter deficits in patients with chronic primary insomnia. Sleep 36 , 999-1007. doi: 10.5665/sleep.2796

Kenet, T., Bibitchkov, D., Tsodyks, M., Grinvald, A., and Arieli, A. (2003). Spontaneously emerging cortical representations of visual attributes. Nature 425, 954-956. doi: 10.1038 /nature 02078

Kirchhoff, F. (2013). "Role of microglia in the normal brain," in Neuroglia, eds H. Kettenmann, and B. R. Ransom (New York, NY: Oxford University Press), 605-613.

Ko, G. Y., Shi, L., and Ko, M. L. (2009). Circadian regulation of ion channels and their functions. J. Neurochem. 110, 1150-1169. doi: $10.1111 / j .1471-4159.2009 .06223 . x$

Kondratova, A. A., Dubrovsky, Y. V., Antoch, M. P., and Kondratov, R. V. (2010). Circadian clock proteins control adaptation to novel environment and memory formation. Aging 2, 285-297. doi: 10.18632/aging.100142

Lavialle, M., Aumann, G., Anlauf, E., Pröls, F., Arpin, M., and Derouiche, A. (2011). Structural plasticity of perisynaptic astrocyte processes involves ezrin and metabotropic glutamate receptors. Proc. Natl. Acad. Sci. U.S.A. 108, 12915-12919. doi: 10.1073/pnas.1100957108

Lavialle, M., and Servière, J. (1993). Circadian fluctuations in GFAP distribution in the Syrian hamster suprachiasmatic nucleus. Neuroreport 4, 1243-1246. doi: 10.1097/00001756-199309000-00008

Le Martelot, G., Claudel, T., Gatfield, D., Schaad, O., Kornmann, B., Lo Sasso, G., et al. (2009). REV-ERBalpha participates in circadian SREBP signaling and bile acid homeostasis. PLoS Biol 7:e1000181. doi: 10.1371/journal.pbio.1000181

Levine, J. M., Stincone, F., and Lee, Y.-S. (1993). Development and differentiation of glial precursor cells in the rat cerebellum. Glia 7, 307-321. doi: $10.1002 /$ glia.440070406

Lin, S.-C., and Bergles, D. E. (2004). Synaptic signaling between neurons and glia. Glia 47, 290-298. doi: 10.1002/glia.20060

Liu, Z., Li, Y., Qian, J., Cui, Y., and Chopp, M. (2014). Plasminogen deficiency causes reduced corticospinal axonal plasticity and functional recovery after stroke in mice. PLoS ONE 9:e94505. doi: 10.1371/journal.pone.0094505

Lo, J. C., Groeger, J. A., Santhi, N., Arbon, E. L., Lazar, A. S., Hasan, S., et al. (2012). Effects of partial and acute total sleep deprivation on performance 
across cognitive domains, individuals and circadian phase. PLoS ONE 7:e45987. doi: 10.1371/journal.pone.0045987

Lohmann, C., and Kessels, H. W. (2014). The developmental stages of synaptic plasticity. J. Physiol. 592, 13-31. doi: 10.1113/jphysiol.2012.235119

Lowrey, P. L., and Takahashi, J. S. (2004). Mammalian circadian biology: elucidating genome-wide levels of temporal organization. Annu. Rev. Genomics Hum. Genet. 5, 407-441. doi: 10.1146/annurev.genom.5.061903.175925

Marpegan, L., Swanstrom, A. E., Chung, K., Simon, T., Haydon, P. G., Khan, S. K., et al. (2011). Circadian regulation of ATP release in astrocytes. J. Neurosci. 31, 8342-8350. doi: 10.1523/JNEUROSCI.6537-10.2011

Martínez-Lozada, Z., and Ortega, A. (2015). Glutamatergic transmission: a matter of three. Neural Plast. 2015, 1-11. doi: 10.1155/2015/787396

Martin, S. J., Grimwood, P. D., and Morris, R. G. (2000). Synaptic plasticity and memory: an evaluation of the hypothesis. Annu. Rev. Neurosci. 23, 649-711. doi: 10.1146/annurev.neuro.23.1.649

Massimini, M., and Amzica, F. (2001). Extracellular calcium fluctuations and intracellular potentials in the cortex during the slow sleep oscillation. J. Neurophysiol. 85, 1346-1350. doi: 10.1152/jn.2001.85.3.1346

Matsumoto, Y., Tsunekawa, Y., Nomura, T., Suto, F., Matsumata, M., Tsuchiya, S., et al. (2011). Differential proliferation rhythm of neural progenitor and oligodendrocyte precursor cells in the young adult hippocampus. PLoS ONE 6:e27628. doi: 10.1371/journal.pone.0027628

McCarthy, G. F., and Leblond, C. P. (1988). Radioautographic evidence for slow astrocyte turnover and modest oligodendrocyte production in the corpus callosum of adult mice infused with $3 \mathrm{H}$-thymidine. J. Comp. Neurol. 271, 589-603. doi: 10.1002/cne.902710409

McEntee, W. J., and Crook, T. H. (1993). Glutamate: its role in learning, memory, and the aging brain. Psychopharmacology 111, 391-401. doi: 10.1007/BF02253527

McKerracher, L., David, S., Jackson, D. L., Kottis, V., Dunn, R. J., and Braun, P. E. (1994). Identification of myelin-associated glycoprotein as a major myelin-derived inhibitor of neurite growth. Neuron 13, 805-811. doi: 10.1016/0896-6273(94)90247-X

Möller-Levet, C. S., Archer, S. N., Bucca, G., Laing, E. E., Slak, A., Kabiljo, R., et al. (2013). Effects of insufficient sleep on circadian rhythmicity and expression amplitude of the human blood transcriptome. Proc. Natl. Acad. Sci. U.S.A. 110, E1132-E1141. doi: 10.1073/pnas.1217154110

Monk, T. H., and Folkard, S. (1978). Concealed inefficiency of late-night study. Nature 273, 296-297. doi: 10.1038/273296a0

Moriguchi, T., Greiner, R. S., and Salem, N. (2000). Behavioral deficits associated with dietary induction of decreased brain docosahexaenoic acid concentration. J. Neurochem. 75, 2563-2573. doi: 10.1046/j.1471-4159.2000.0752563.x

Moriya, T., Yoshinobu, Y., Kouzu, Y., Katoh, A., Gomi, H., Ikeda, M., et al. (2000). Involvement of glial fibrillary acidic protein (GFAP) expressed in astroglial cells in circadian rhythm under constant lighting conditions in mice. J. Neurosci. Res. 60, 212-218. doi: 10.1002/(SICI)1097-4547(20000415)60:2\&lt;212::AIDJNR10\&gt;3.0.CO;2-P

Nakazato, R., Takarada, T., Yamamoto, T., Hotta, S., Hinoi, E., and Yoneda, Y. (2011). Selective upregulation of Per1 mRNA expression by ATP through activation of $\mathrm{P} 2 \mathrm{X} 7$ purinergic receptors expressed in microglial cells. J. Pharmacol. Sci. 116, 350-361. doi: 10.1254/jphs.11069FP

Newman, L. A., Korol, D. L., and Gold, P. E. (2011). Lactate produced by glycogenolysis in astrocytes regulates memory processing. PLoS ONE 6:e28427. doi: 10.1371 /journal.pone.0028427

Nishida, H., and Okabe, S. (2007). Direct astrocytic contacts regulate local maturation of dendritic spines. J. Neurosci. 27, 331-340. doi: 10.1523/JNEUROSCI.4466-06.2007

Panda, S., Antoch, M. P., Miller, B. H., Su, A. I., Schook, A. B., Straume, M., et al. (2002). Coordinated transcription of key pathways in the mouse by the circadian clock. Cell 109, 307-320. doi: 10.1016/S0092-8674(02)00722-5

Parpura, V., Basarsky, T. A., Liu, F., Jeftinija, K., Jeftinija, S., and Haydon, P. G. (1994). Glutamate-mediated astrocyte-neuron signalling. Nature 369, 744-747. doi: $10.1038 / 369744 \mathrm{a} 0$

Parpura, V., and Zorec, R. (2010). Gliotransmission: exocytotic release from astrocytes. Brain Res. Rev. 63, 83-92. doi: 10.1016/j.brainresrev.2009.11.008

Pascual, O., Ben Achour, S., Rostaing, P., Triller, A., and Bessis, A. (2012). Microglia activation triggers astrocyte-mediated modulation of excitatory neurotransmission. Proc. Natl. Acad. Sci. U.S.A. 109, E197-E205 doi: 10.1073/pnas.1111098109

Pascual, O., Casper, K. B., Kubera, C., Zhang, J., Revilla-Sanchez, R., Sul, J.-Y., et al. (2005). Astrocytic purinergic signaling coordinates synaptic networks. Science 310, 113-116. doi: 10.1126/science.1116916

Perea, G., Navarrete, M., and Araque, A. (2009). Tripartite synapses: astrocytes process and control synaptic information. Trends Neurosci. 32, 421-431. doi: 10.1016/j.tins.2009.05.001

Poskanzer, K. E., and Yuste, R. (2011). Astrocytic regulation of cortical UP states. Proc. Natl. Acad. Sci. U.S.A. 108, 18453-18458. doi: 10.1073/pnas.1112378108

Poskanzer, K. E., and Yuste, R. (2016). Astrocytes regulate cortical state switching in vivo. Proc. Natl. Acad. Sci. U.S.A. 113, E2675-E2684. doi: 10.1073/pnas.1520759113

Preitner, N., Damiola, F., Lopez-Molina, L., Zakany, J., Duboule, D., Albrecht, U., et al. (2002). The orphan nuclear receptor REV-ERBalpha controls circadian transcription within the positive limb of the mammalian circadian oscillator. Cell 110, 251-260. doi: 10.1016/S0092-8674(02)00825-5

Ramaswamy, S., and Muller, E. B. (2015). Cell-type specific modulation of neocortical UP and DOWN states. Front. Cell. Neurosci. 9:370. doi: $10.3389 /$ fncel.2015.00370

Rawashdeh, O., de Borsetti, N. H., Roman, G., and Cahill, G. M. (2007). Melatonin suppresses nighttime memory formation in zebrafish. Science 318, 1144-1146. doi: $10.1126 /$ science. 1148564

Reppert, S. M., and Weaver, D. R. (2001). Molecular analysis of mammalian circadian rhythms. Annu. Rev. Physiol. 63, 647-676. doi: 10.1146/annurev.physiol.63.1.647

Reppert, S. M., and Weaver, D. R. (2002). Coordination of circadian timing in mammals. Nature 418, 935-941. doi: 10.1038/nature00965

Rudy, J. W., and Pugh, C. R. (1998). Time of conditioning selectively influences contextual fear conditioning: further support for a multiple-memory systems view of fear conditioning. J. Exp. Psychol. Anim. Behav. Process. 24, 316-324. doi: 10.1037/0097-7403.24.3.316

Saab, A. S., Neumeyer, A., Jahn, H. M., Cupido, A., Šimek, A. A. M., Boele, H.J., et al. (2012). Bergmann glial AMPA receptors are required for fine motor coordination. Science 337, 749-753. doi: 10.1126/science. 1221140

Sakai, T., Tamura, T., Kitamoto, T., and Kidokoro, Y. (2004). A clock gene, period, plays a key role in long-term memory formation in Drosophila. Proc. Natl. Acad. Sci. U.S.A. 101, 16058-16063. doi: 10.1073/pnas.0401472101

Sanz, J. M., and Di Virgilio, F. (2000). Kinetics and mechanism of ATPdependent IL-1 beta release from microglial cells. J. Immunol. 164, 4893-4898. doi: 10.4049/jimmunol.164.9.4893

Schibler, U., and Sassone-Corsi, P. (2002). A web of circadian pacemakers. Cell 111, 919-922. doi: 10.1016/S0092-8674(02)01225-4

Shibuki, K., Gomi, H., Chen, L., Bao, S., Kim, J. J., Wakatsuki, H., et al. (1996) Deficient cerebellar long-term depression, impaired eyeblink conditioning, and normal motor coordination in GFAP mutant mice. Neuron 16, 587-599. doi: 10.1016/S0896-6273(00)80078-1

Sierra, A., Abiega, O., Shahraz, A., and Neumann, H. (2013). Janus-faced microglia: beneficial and detrimental consequences of microglial phagocytosis. Front. Cell. Neurosci. 7:6. doi: 10.3389/fncel.2013.00006

Spanagel, R., Pendyala, G., Abarca, C., Zghoul, T., Sanchis-Segura, C., Magnone, M. C., et al. (2005). The clock gene Per2 influences the glutamatergic system and modulates alcohol consumption. Nat. Med. 11, 35-42. doi: 10.1038/nm1163

Steriade, M., Nuñez, A., and Amzica, F. (1993). Intracellular analysis of relations between the slow ( $\& 1 \mathrm{lt} ; 1 \mathrm{~Hz}$ ) neocortical oscillation and other sleep rhythms of the electroencephalogram. J. Neurosci. 13, 3266-3283.

Steriade, M., Timofeev, I., and Grenier, F. (2001). Natural waking and sleep states: a view from inside neocortical neurons. J. Neurophysiol. 85, 1969-1985. doi: 10.1152/jn.2001.85.5.1969

Stratmann, M., and Schibler, U. (2006). Properties, entrainment, and physiological functions of mammalian peripheral oscillators. J. Biol. Rhythms 21, 494-506. doi: 10.1177/0748730406293889

Suzuki, A., Stern, S. A., Bozdagi, O., Huntley, G. W., Walker, R. H., Magistretti, P. J., et al. (2011). Astrocyte-neuron lactate transport is required for long-term memory formation. Cell 144, 810-823. doi: 10.1016/j.cell.2011.02.018

Suzuki, T., Hide, I., Ido, K., Kohsaka, S., Inoue, K., and Nakata, Y. (2004). Production and release of neuroprotective tumor necrosis 
factor by P2X7 receptor-activated microglia. J. Neurosci. 24, 1-7. doi: 10.1523/JNEUROSCI.3792-03.2004

Takeuchi, T., Iwanaga, M., and Harada, E. (2003). Possible regulatory mechanism of DHA-induced anti-stress reaction in rats. Brain Res. 964, 136-143. doi: 10.1016/S0006-8993(02)04113-6

Theodosis, D. T., Poulain, D. A., and Olliet, S. H. (2008). Activity-dependent structural and functional plasticity of astrocyte-neuron interactions. Physiol. Rev. 88, 983-1008. doi: 10.1152/physrev.00036.2007

Thomson, A. M., Walker, V. E., and Flynn, D. M. (1989). Glycine enhances NMDA-receptor mediated synaptic potentials in neocortical slices. Nature 338, 422-424. doi: 10.1038/338422a0

Turrigiano, G. (2011). Too many cooks? Intrinsic and synaptic homeostatic mechanisms in cortical circuit refinement. Annu. Rev. Neurosci. 34, 89-103. doi: 10.1146/annurev-neuro-060909-153238

Tzingounis, A. V., and Wadiche, J. I. (2007). Glutamate transporters: confining runaway excitation by shaping synaptic transmission. Nat. Rev. Neurosci. 8, 935-947. doi: 10.1038/nrn2274

Valentinuzzi, V. S., Menna-Barreto, L., and Xavier, G. F. (2004). Effect of circadian phase on performance of rats in the Morris water maze task. J. Biol. Rhythms 19, 312-324. doi: $10.1177 / 0748730404265688$

Van der Zee, E. A., Havekes, R., Barf, R. P., Hut, R. A., Nijholt, I. M., Jacobs, E. H., et al. (2008). Circadian time-place learning in mice depends on Cry genes. Curr. Biol. 18, 844-848. doi: 10.1016/j.cub.2008.04.077

Wainwright, P. E., Xing, H. C., Mutsaers, L., McCutcheon, D., and Kyle, D. (1997). Arachidonic acid offsets the effects on mouse brain and behavior of a diet with a low (n-6):(n-3) ratio and very high levels of docosahexaenoic acid. J. Nutr. 127, 184-193.

Walker, M. P., and Stickgold, R. (2006). Sleep, memory, and plasticity. Annu. Rev. Psychol. 57, 139-166. doi: 10.1146/annurev.psych.56.091103.070307

Wang, K. C., Koprivica, V., Kim, J. A., Sivasankaran, R., Guo, Y., Neve, R. L., et al. (2002). Oligodendrocyte-myelin glycoprotein is a Nogo receptor ligand that inhibits neurite outgrowth. Nature 417, 941-944. doi: 10.1038/nature 00867
Wang, L. M.-C., Dragich, J. M., Kudo, T., Odom, I. H., Welsh, D. K., O’Dell, T. J., et al. (2009). Expression of the circadian clock gene Period2 in the hippocampus: possible implications for synaptic plasticity and learned behaviour. ASN Neuro 1:e00012. doi: 10.1042/AN20090020

Winocur, G., and Hasher, L. (2004). Age and time-of-day effects on learning and memory in a non-matching-to-sample test. Neurobiol. Aging 25, 1107-1115. doi: 10.1016/j.neurobiolaging.2003.10.005

Womac, A. D., Burkeen, J. F., Neuendorff, N., Earnest, D. J., and Zoran, M. J. (2009). Circadian rhythms of extracellular ATP accumulation in suprachiasmatic nucleus cells and cultured astrocytes. Eur. J. Neurosci. 30, 869-876. doi: 10.1111/j.1460-9568.2009.06874.x

Wurtz, C. C., and Ellisman, M. H. (1986). Alterations in the ultrastructure of peripheral nodes of Ranvier associated with repetitive action potential propagation. J. Neurosci. 6, 3133-3143.

Yamamoto, N., Saitoh, M., Moriuchi, A., Nomura, M., and Okuyama, H. (1987). Effect of dietary alpha-linolenate/linoleate balance on brain lipid compositions and learning ability of rats. J. Lipid Res. 28, 144-151.

Zhong, Y., Zhou, L.-J., Ren, W.-J., Xin, W.-J., Li, Y.-Y., Zhang, T., et al. (2010). The direction of synaptic plasticity mediated by $\mathrm{C}$-fibers in spinal dorsal horn is decided by Src-family kinases in microglia: the role of tumor necrosis factor- $\alpha$. Brain Behav. Immun. 24, 874-880. doi: 10.1016/j.bbi.2010.01.007

Conflict of Interest Statement: The authors declare that the research was conducted in the absence of any commercial or financial relationships that could be construed as a potential conflict of interest.

Copyright (c) 2018 Chi-Castañeda and Ortega. This is an open-access article distributed under the terms of the Creative Commons Attribution License (CC $B Y)$. The use, distribution or reproduction in other forums is permitted, provided the original author(s) and the copyright owner are credited and that the original publication in this journal is cited, in accordance with accepted academic practice. No use, distribution or reproduction is permitted which does not comply with these terms. 